\title{
Survey of Awareness and Perceptions of Canadians on the Benefits and Risks of Clinical Trials
}

\author{
Therapeutic Innovation \\ \& Regulatory Science \\ 2019, Vol. 53(5) 669-677 \\ (C) The Author(s) 2018 \\ (c) (i) (5) \\ Article reuse guidelines: \\ sagepub.com/journals-permissions \\ DOI: I0.1 I77/2I68479018805433 \\ tirs.sagepub.com
}

\author{
Donald J. Willison, ScD', Dawn P. Richards, PhD $^{2}$, Alison Orth, BBA ${ }^{3}$, \\ Heather Harris, $\mathrm{MSc}^{4}$, and Susan Marlin, $\mathrm{MSc}^{2}$
}

\begin{abstract}
Background: Little is known about the Canadian public's perspective regarding clinical trials.

Methods: We surveyed 1602 Ontario and British Columbia residents to ascertain their understanding of and willingness to participate in clinical trials.

Results: Clinical trials are regarded positively with overall perceptions that they provide societal and personal benefits. Most respondents were somewhat (49\%) or very willing (19\%) to participate in a clinical trial. This increased with age and level of education. It was also greater among those with poor or very poor health, those with multiple chronic conditions, and those who had previously been invited into a clinical trial, all of which were correlated with age. Still, there was room for improvement in awareness and understanding of clinical trials. Forty-three percent of those surveyed felt not very informed or not at all informed and $37 \%$ had no opinion regarding clinical trials. Respondents would most often turn to their treating physician if considering participating in a clinical trial and least often to social media.

Conclusion: While Canadians' views about clinical trials are generally positive, they are somewhat muted and a significant minority feels poorly or not at all informed. They are less willing to participate in clinical research than Americans and are roughly equivalent to Europeans. While clinicians are the top choice for learning about clinical trials, they have little or no training and little time for this role. As we move toward integrating clinical trials into the practice setting, these issues of time, training, and resources must be addressed.
\end{abstract}

\section{Keywords}

public opinion, clinical trials, Canada

\section{Background}

Canada has adopted a strategy for patient-oriented research that integrates research into the health care system and clinical practice. ${ }^{1}$ Clinical trials are the gold standard for answering questions about what therapies do and do not work. Yet clinical trials in Canada and elsewhere struggle to meet enrolment goals, slowing down our ability to answer those questions around effectiveness of therapies. ${ }^{2,3}$ Declining enrolment into clinical trials has been identified as a priority issue to be addressed in Canada's Strategy for Patient-Oriented Research. ${ }^{4}$ There are many possible reasons for this decline in enrolment, including a lack of public awareness of clinical trials in general, lack of ready access to clinical trials, and willingness to participate by eligible patients or healthy participants. ${ }^{5-8}$

There is currently very little information regarding the understanding and attitudes of the Canadian public toward clinical trials. Two Canadian studies chiefly sampled patients or their significant others rather than the general public. ${ }^{9,10}$ A third study included Canadians as part of a general North American survey, but the number of Canadian participants was not reported and, on communicating with the senior author, we were advised that the number of Canadians in the survey was "negligible." Consequently, those wishing to understand attitudes toward participation in clinical trials in Canada have had to rely chiefly on data from the United States and elsewhere. ${ }^{8,11-13}$

Clinical Trials Ontario (CTO) and Clinical Trials BC ${ }^{\mathrm{i}}$ surveyed residents of Ontario and British Columbia to determine their awareness of clinical trials, their perceptions of the

\footnotetext{
' Institute of Health Policy, Management and Evaluation, University of Toronto, Toronto, Ontario, Canada

${ }^{2}$ Clinical Trials Ontario, Toronto, Ontario, Canada

${ }^{3}$ Clinical Trials BC, Vancouver, British Columbia, Canada

${ }^{4}$ Can-SOLVE CKD Network, Vancouver, British Columbia, Canada
}

Corresponding Author:

Donald Willison, Associate Professor, Institute of Health Policy, Management and Evaluation, University of Toronto, Toronto, ON M5T3M6, Canada.

Email: don.willison@utoronto.ca 
benefits and risks associated with potential participation, and their willingness and motivation to participate in a clinical trial. This survey was one component of a greater patient and public engagement strategy to help these organizations better understand reasons for participation in clinical trials and to develop mechanisms to increase patient and public engagement with and participation in clinical trials.

\section{Methods}

Clinical Trials Ontario and Clinical Trials BC developed the survey and contracted with Ipsos Canada to administer the survey electronically, drawing from registered users of the i-Say online survey rewards community, operated by Ipsos. ${ }^{14}$ The target sample size was 1600 panelists - 800 in British Columbia and 800 in Ontario. Stratified sampling was used, based on age, gender, and region. Details of the panel construction and sampling process are available in Online Appendix 1. The survey was administered between July 28 and August 12, 2015.

The survey questions focused on respondents' awareness of and attitudes toward clinical trials; willingness to participate in a clinical trial; perceptions of the risks, benefits, and motivators for participating in a clinical trial; and the sources to which they would turn for information. The questions in the survey were adapted, with permission, from a 2013 survey conducted by the Center for Information and Study on Clinical Research Participation (CISCRP), an independent Boston-based not-for-profit organization that has conducted several American and international surveys on public perceptions of and participation in clinical research over the past several years. ${ }^{15,16}$ The complete survey is available in Online Appendix 2.

The data were cleaned and deidentified by Ipsos, and provided to the research team to be analyzed. Cleaning included removal from the data set of the records of individuals who complete a survey in a much shorter time than would be anticipated by its length and those who provided the same response category for blocks of questions.

The research team conducted descriptive statistics of the survey findings. Selected questions were subjected to crosstabulations by respondent age, gender, education, and health status. As our analyses were hypothesis generating, we did not go beyond simple cross-tabulations.

The study was approved by the University of Toronto Health Sciences Research Ethics Board.

\section{Results}

The survey was completed by 1602 adults ( 800 in British Columbia; 802 in Ontario). Responses from the 2 provinces have been combined, as response profiles across provinces were virtually identical. The demographics of the population has been summarized in Table 1 .

Eleven percent of those surveyed had been invited at some time in the past to participate in a clinical trial; $6 \%$ reported someone close to them had been invited in the past. Those who had been invited were more likely to be older: $17 \%$ of respondents 65 years or older had been invited in the past to participate in a clinical trial. By contrast, $13 \%$ of those 55 to 64 years, $10 \%$ of those 35 to 54 years, and $8 \%$ of those 18 to 34 years of age had been invited in the past to participate in a clinical trial. A higher proportion (21\%) of those who reported 2 or more health conditions reported having been invited in the past to participate in a clinical trial.

Table 2 summarizes respondents' knowledge and perceptions of clinical trials. Most described their knowledge of clinical trials as either somewhat $(48 \%)$ or very well informed (9\%). Respondents were more likely to regard themselves as very well informed if (1) they described their health as "excellent" (22\%); (2) they possessed graduate or postgraduate university education (17\%); or (3) they possessed a professional degree (20\%). In addition, we noted that higher proportions of those who identified their gender as "other" or "prefer not to answer" reported they were very well informed (28\%) or not at all informed (22\%). As this was a very small group $(n=18)$ and responses often polarized, we kept our findings in the tables but do not report further on this group.

Overall, $59 \%$ of respondents expressed either somewhat positive $(41 \%)$ or very positive $(18 \%)$ views toward clinical trials. Thirty-seven percent had neither positive nor negative views and $4 \%$ had negative or strongly negative views of clinical trials. There was little variation across age and between males and females. Respondents who expressed very positive views of clinical trials included those who described their health as "excellent" ( $28 \%$ ) or "poor or very poor" $(29 \%)$, those with higher levels of education (graduate and postgraduate $24 \%$; professional degrees $22 \%$ ) and those who had 2 or more chronic health conditions (28\%).

Most respondents reported that clinical trials are either "somewhat safe" $(75 \%)$ or "very safe" (14\%). A higher proportion of respondents aged $\geq 65$ years reported that clinical trials were somewhat or very safe. In addition, those who described their health as "excellent," those with higher education attainment, and those with 2 or more chronic conditions were more inclined to perceive clinical trials as very safe.

The greatest concerns about participating in a clinical trial were the possibility of encountering side effects $(81 \%)$ and possible risks to overall health (52\%). A further $33 \%$ of respondents identified the possibility of receiving a placebo as a "risk." Twenty-one percent had concerns over possible disclosure of their private medical information. Five percent felt there were no risks to participation.

Self-assessed knowledge of clinical trials was strongly correlated with positive views about clinical trials and about the safety of clinical trials. (Pearson chi-square, $P=.000$ ). For example, $91 \%$ of those who felt very well informed had either very positive $(57 \%)$ or somewhat positive (34\%) views of clinical trials and $48 \%$ felt they were very safe. By contrast, only $19 \%$ of those who described themselves as not at all informed about clinical trials felt very $(5 \%)$ or somewhat positive $(14 \%)$ about clinical trials and $6 \%$ believed them to be very safe. 
Table I. Description of Survey Participants. ${ }^{\mathrm{a}}$

\begin{tabular}{|c|c|c|c|}
\hline Variable & Category & \multicolumn{2}{|c|}{ Response } \\
\hline \multirow[t]{3}{*}{ Gender } & Male & $78 \mid(49 \%)$ & $49 \%$ \\
\hline & Female & $803(50 \%)$ & $51 \%$ \\
\hline & Other/Prefer not to answer & $18(1 \%)$ & \\
\hline \multirow[t]{2}{*}{ Age group, $y$} & $18-34$ & $449(28 \%)$ & $25 \%{ }^{\mathrm{b}}$ \\
\hline & $\geq 65$ & $322(20 \%)$ & $22 \%$ \\
\hline \multirow[t]{5}{*}{ Highest education } & $\overline{\text { High school diploma or less }}$ & $321(20 \%)$ & $35 \%^{c}$ \\
\hline & Some university or college / or trade or technical diploma & $363(23 \%)$ & \\
\hline & College diploma or university degree & $626(39 \%)$ & \\
\hline & University graduate or post-graduate degree & 244 (15\%) & \\
\hline & Professional degree & $46(3 \%)$ & \\
\hline & Homemaking/caregiving & $74(5 \%)$ & \\
\hline & Studying & $76(5 \%)$ & \\
\hline & Looking for work & $63(4 \%)$ & \\
\hline & Long-term disability & $44(3 \%)$ & \\
\hline & Maternity/paternity leave & $7(<1 \%)$ & \\
\hline \multirow[t]{4}{*}{ Self-reported health } & Excellent & $245(15 \%)$ & $\mathrm{N} / \mathrm{A}$ \\
\hline & Good & $978(61 \%)$ & \\
\hline & Fair & $327(20 \%)$ & \\
\hline & Poor or very poor & $52(3 \%)$ & \\
\hline \multirow[t]{3}{*}{ Chronic health conditions } & None & $958(60 \%)$ & $N / A$ \\
\hline & One & 362 (23\%) & \\
\hline & Two or more & $282(18 \%)$ & \\
\hline \multirow[t]{7}{*}{ Household income } & $<\$ 15,000$ & $84(5 \%)$ & $6 \%$ \\
\hline & $\$ 15,000-\$ 29,999$ & $182(1 \mid \%)$ & $12 \%$ \\
\hline & $\$ 30,000-\$ 49,999$ & $252(16 \%)$ & $17 \%$ \\
\hline & $\$ 50,000-\$ 74,999$ & $35 \mathrm{I}(22 \%)$ & $22 \%$ \\
\hline & $\$ 75,000-\$ 100,000$ & $259(16 \%)$ & $11 \%$ \\
\hline & $>\$ 100,000$ & 243 (I5\%) & $32 \%$ \\
\hline & Prefer not to answer & $231(14 \%)$ & \\
\hline
\end{tabular}

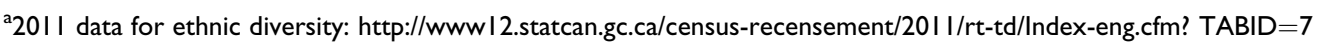

201 I data for education and labor available at: http://www/2.statcan.gc.ca/census-recensement/20 I I/rt-td/lndex-eng.cfm?TABID=8 Census Canada 2016 data sources:

Age and gender: http://www/2.statcan.gc.ca/census-recensement/2016/dp-pd/dt-td/Rp-eng.cfm?\&APATH=3\&DETAIL $=0 \& D I M=0 \& F L=A \& F R E E=0 \& G C=0 \&$ $\mathrm{GID}=0 \& \mathrm{GK}=0 \& \mathrm{GRP}=1 \& \mathrm{PID}=109523 \& \mathrm{PRID}=10 \& \mathrm{PTYPE}=109445 \& S=0 \& S \mathrm{HOWALL}=0 \& S U B=0 \& T$ emporal $=2016 \& \mathrm{THEME}=1 \mid \mathrm{5} \& \mathrm{VID}=0 \& \mathrm{VNAMEE}=\&$ VNAMEF $=$

Ethnic origin: http://www 12 statcan.gc.ca/census-recensement/2016/dp-pd/dt-td/Rp-eng.cfm?\&APATH $=3 \& D E T A I L=0 \& D I M=0 \& F L=A \& F R E E=0 \& G C=0 \&$ $\mathrm{GID}=0 \& \mathrm{GK}=0 \& \mathrm{GRP}=1 \& \mathrm{PID}=1 \mathrm{I0528} \& \mathrm{PRID}=10 \& \mathrm{PTYPE}=109445 \& \mathrm{~S}=0 \& \mathrm{SHOWALL}=0 \& S \mathrm{~B}=0 \& \mathrm{Temporal}=2017 \& \mathrm{THEME}=120 \& \mathrm{VID}=0 \& \mathrm{VNAMEE}=\&$ VNAMEF $=$

Income: http://wwwl2.statcan.gc.ca/census-recensement/2016/dp-pd/dt-td/Rp-eng.cfm?\&APATH=3\&DETAIL =0\&DIM=0\&FL=A\&FREE=0\&GC =0\&GID $=$ $0 \& G K=0 \& G R P=\mid \& P I D=110185 \& P R I D=10 \& P T Y P E=109445 \& S=0 \& S H O W A L L=0 \& S U B=0 \& T$ emporal $=2016 \& T H E M E=1 \mid 9 \& V I D=0 \& V N A M E E=\&$

VNAMEF $=$

${ }^{b}$ Age 20-34.

'Source: https://www 2.statcan.gc.ca/census-recensement/20I 6/dp-pd/hlt-fst/edu-sco/Table.cfm?Lang $=$ E\&T $=||$ \&Geo $=00 \& V i e w=2 \& A g e=2$

${ }^{d}$ Source: https://www 12 .statcan.gc.ca/census-recensement/20I6/dp-pd/hlt-fst/lab-tra/Table.cfm?Lang $=E \& T=I I \& G e o=00$ 


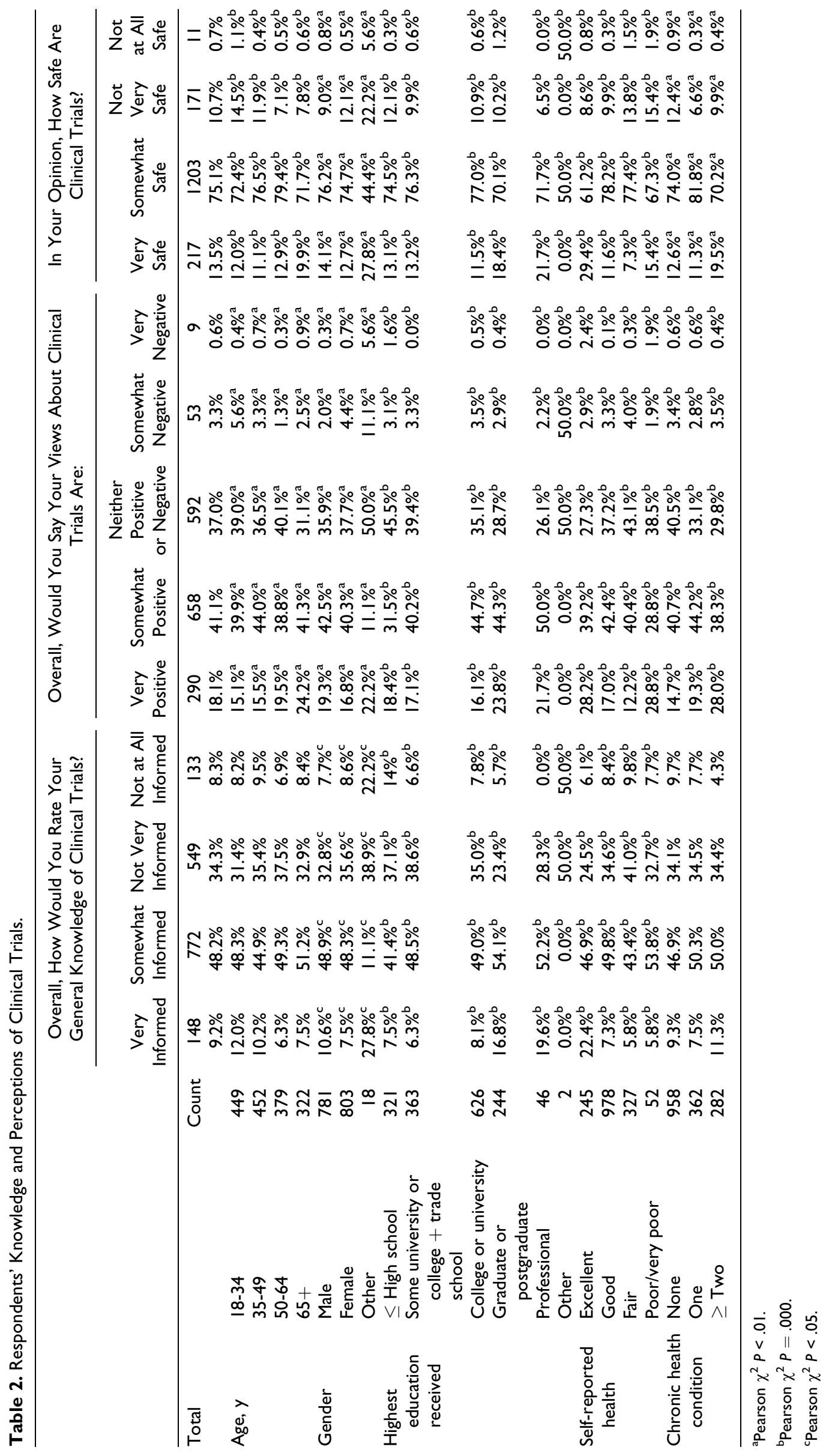


Table 3. Willingness to Participate in a Clinical Trial.

\begin{tabular}{|c|c|c|c|c|c|c|c|}
\hline & & & \multicolumn{5}{|c|}{$\begin{array}{c}\text { If Given the Opportunity, How Willing Would You Be to } \\
\text { Participate in a Clinical Trial? }\end{array}$} \\
\hline & & & $\begin{array}{c}\text { Very } \\
\text { Willing }\end{array}$ & $\begin{array}{c}\text { Somewhat } \\
\text { Willing }\end{array}$ & $\begin{array}{c}\text { Not Very } \\
\text { Willing }\end{array}$ & $\begin{array}{c}\text { Not at } \\
\text { All Willing }\end{array}$ & Unsure \\
\hline \multirow[t]{2}{*}{ Total } & & Count & 299 & 789 & 243 & 78 & 193 \\
\hline & & & $18.7 \%$ & $49.3 \%$ & $15.2 \%$ & $4.9 \%$ & $12.0 \%$ \\
\hline & 50 to 65 & 379 & $20.8 \%^{\mathrm{a}}$ & $52.8 \%{ }^{\mathrm{a}}$ & $10.3 \%^{\mathrm{a}}$ & $3.4 \%^{\mathrm{a}}$ & $12.7 \%^{\mathrm{a}}$ \\
\hline & 65 years & 322 & $20.5 \%{ }^{\mathrm{a}}$ & $48.1 \%^{\mathrm{a}}$ & $14.3 \%^{\mathrm{a}}$ & $5.3 \%^{\mathrm{a}}$ & $11.8 \%^{\mathrm{a}}$ \\
\hline \multirow[t]{3}{*}{ Gender } & Male & 781 & $18.8 \%^{\mathrm{a}}$ & $51.0 \%{ }^{\mathrm{a}}$ & $14.6 \%^{\mathrm{a}}$ & $4.2 \%^{\mathrm{a}}$ & $11.4 \%^{\mathrm{a}}$ \\
\hline & Female & 803 & $18.2 \%^{\mathrm{a}}$ & $48.6 \%^{\mathrm{a}}$ & $15.8 \%^{\mathrm{a}}$ & $5.2 \%^{\mathrm{a}}$ & $12.2 \%^{\mathrm{a}}$ \\
\hline & Other & 18 & $33.3 \%^{\mathrm{a}}$ & $5.6 \%^{\mathrm{a}}$ & $11.1 \%^{\mathrm{a}}$ & $16.7 \%^{\mathrm{a}}$ & $33.3 \%^{\mathrm{a}}$ \\
\hline \multirow[t]{2}{*}{ Highest education received } & $\leq$ High school & 321 & $17.4 \%^{\mathrm{a}}$ & $43.6 \%^{\mathrm{a}}$ & $18.4 \%^{\mathrm{a}}$ & $5.3 \%^{\mathrm{a}}$ & $15.3 \%^{\mathrm{a}}$ \\
\hline & Other & 2 & $0.0 \%{ }^{\mathrm{a}}$ & $0.0 \%^{\mathrm{a}}$ & $0.0 \%^{\mathrm{a}}$ & $0.0 \%^{\mathrm{a}}$ & $100.0 \%^{\mathrm{a}}$ \\
\hline \multirow[t]{4}{*}{ Self-reported health } & Excellent & $24 \overline{5}$ & $27.3 \%^{\mathrm{b}}$ & $40.8 \%^{\mathrm{b}}$ & $17.6 \%^{\mathrm{b}}$ & $6.9 \%^{\mathrm{b}}$ & $7.3 \%^{\mathrm{b}}$ \\
\hline & Good & 978 & $15.4 \%^{\mathrm{b}}$ & $52.6 \%$ & $15.0 \%{ }^{b}$ & $4.2 \%^{b}$ & $12.8 \%^{\mathrm{b}}$ \\
\hline & Fair & 327 & $19.3 \%^{\mathrm{b}}$ & $46.5 \%{ }^{\mathrm{b}}$ & $15.6 \%$ & $5.5 \%$ & $13.1 \%^{\mathrm{b}}$ \\
\hline & Poor or very poor & 52 & $34.6 \%^{\mathrm{b}}$ & $44.2 \%^{\mathrm{b}}$ & $3.8 \%^{\mathrm{b}}$ & $3.8 \%^{b}$ & $13.5 \%^{\mathrm{b}}$ \\
\hline \multirow[t]{3}{*}{ Chronic health conditions } & None & 958 & $14.2 \%^{\mathrm{b}}$ & $49.3 \%^{b}$ & $17.1 \%^{b}$ & $5.6 \%{ }^{\mathrm{b}}$ & $13.8 \%^{\mathrm{b}}$ \\
\hline & One & 362 & $21.5 \%^{\mathrm{b}}$ & $51.4 \%^{\mathrm{b}}$ & $14.1 \%^{\mathrm{b}}$ & $4.4 \%^{\mathrm{b}}$ & $8.6 \%^{\mathrm{b}}$ \\
\hline & $\geq$ Two & 282 & $30.1 \%$ & $46.5 \%^{\mathrm{b}}$ & $9.9 \%^{b}$ & $2.8 \%^{\mathrm{b}}$ & $10.6 \%^{\mathrm{b}}$ \\
\hline Invited before to participate & $\bar{N} o$ & 1198 & $16.4 \%^{\mathrm{b}}$ & $48.8 \%^{b}$ & $16.0 \%^{\mathrm{b}}$ & $5.6 \%$ & $13.2 \%$ \\
\hline \multirow[t]{3}{*}{ in a clinical trial? } & I have & 180 & $35.6 \%^{\mathrm{b}}$ & $51.1 \%$ & $8.3 \%^{\mathrm{b}}$ & $2.2 \%^{\mathrm{b}}$ & $2.8 \%^{\mathrm{b}}$ \\
\hline & Someone close to me & 92 & $23.9 \%^{\mathrm{b}}$ & $50.0 \%^{b}$ & $10.9 \%^{\mathrm{b}}$ & $2.2 \%$ & $13.0 \%$ \\
\hline & Unsure or prefer not to answer & 132 & $12.9 \%^{\mathrm{b}}$ & $50.0 \%{ }^{\mathrm{b}}$ & $19.7 \%^{\mathrm{b}}$ & $3.8 \%^{b}$ & $13.6 \%^{\mathrm{b}}$ \\
\hline
\end{tabular}

a Pearson $\chi^{2} P<.01$.

${ }^{\mathrm{b}}$ Pearson $\chi^{2} P=.000$.

cPearson $\chi^{2} P<.05$.

If given the opportunity, most respondents were either somewhat $(49 \%)$ or very willing $(19 \%)$ to participate in a clinical trial (Table 3). Willingness to participate generally increased with age and with level of education. It was also greater among those with poor or very poor health, those with multiple chronic conditions, and those who had been invited before into a clinical trial, all of which were correlated with age.

The chief circumstances that would influence respondents' participation in a clinical trial were personal in nature, including

- if the respondent thought the treatment would help $(83 \%)$ or cure them $(79 \%)$,

- if the respondent had a terminal (78\%) or chronic illness (78\%),

- if there were no other medical option (78\%).

Other considerations were logistical, including how far one had to travel $(65 \%)$ and the time commitment (48\%).
When asked to consider societal and personal benefits of participation in clinical research, respondents were more inclined to identify societal benefits of clinical trials over personal benefits (Figure 1). For example, $78 \%$ indicated that participation in clinical trials may help advance science; $78 \%$ felt that it may help save or improve the lives of patients; and $64 \%$ indicated that it may improve the health care system. By way of personal benefits, $67 \%$ felt that participation may improve their own health; $47 \%$ felt that they would probably get more time and attention from medical experts; $45 \%$ felt they may also get free care or medications; $40 \%$ felt it may help them understand their disease; and $49 \%$ felt they would derive personal satisfaction from knowing that they were helping others.

Advancing science and improving the health care system were identified more often among younger respondents. Improving the lives of patients was more often cited by older respondents. Compensation for participation (48\%) was cited as a benefit particularly among younger respondents. 


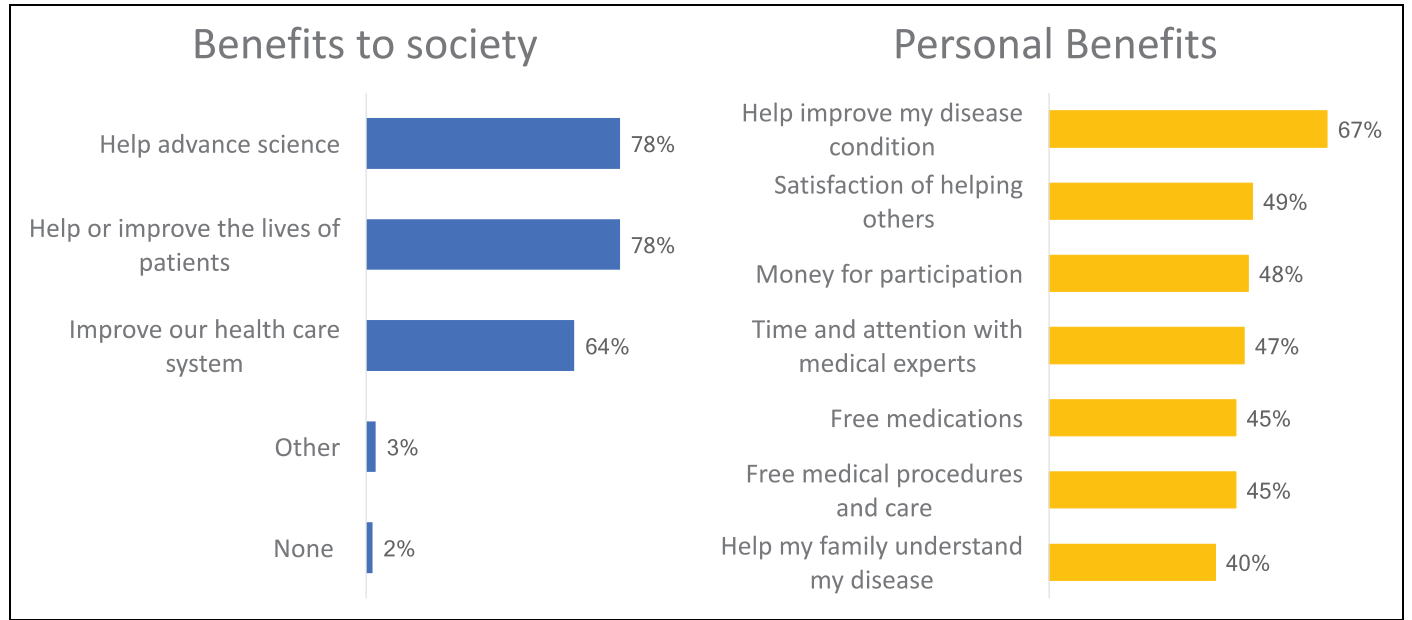

Figure I. Perceived Benefits of Clinical Trial Participation.

A substantial minority believed either strongly $(8 \%)$ or somewhat $(30 \%)$ that people who participate in clinical trials are gambling with their health. A minority also agreed either strongly $(6 \%)$ or somewhat $(21 \%)$ that participants in clinical trials are treated "like experimental test subjects, not people."

Family physicians (77\%) and specialty physicians (55\%) were the sources to which respondents would most often turn for information if considering participating in a clinical trial. This was particularly the case among older respondents (Table 4). However, across all subgroups, family physicians were the top-ranked source to which people would turn for information. Following physicians, older respondents were more inclined to turn to more formal sources like a disease group or patient advocacy group. While still relying heavily on physicians, younger respondents were more inclined to turn to friends and family over more formal advocacy organizations. Across all age groups, the Internet was an important source of information for about one-third of respondents. Conventional media (television, newspapers, etc) and social media (Twitter, Facebook, etc) were the least frequently nominated sources of information across all groups.

\section{Discussion}

Generally, Canadians regard clinical trials positively, with overall perceptions that they provide societal and personal benefit. Support for and willingness to participate in clinical trials increased with age and was greatest among those with multiple chronic health conditions, those with higher levels of education and those who had previously participated in clinical trials.

The association of willingness to participate with age is inconsistent across studies. Nelson and colleagues found a lower willingness to participate among those aged 18-34, although the effect size of age was small. ${ }^{8}$ Two other studies found no difference by age, ${ }^{10,17}$ and Trauth and colleagues found a nonmonotonic relationship in which middle-aged respondents had the greatest willingness to participate in a medical research study. ${ }^{12}$

The finding that those with high-school education or less are somewhat less willing to participate in medical research is consistent with other recent surveys of the general population. ${ }^{15,17}$ However, in a Canadian study of cancer patients, Jones and colleagues found a substantially lower willingness to participate among those with a college or university degree (52\%) compared with those with high school or less (82\%). ${ }^{10}$

The positive association of prior participation with willingness to participate in research suggests that their prior participation in clinical research was a positive experience. The finding that $43 \%$ of respondents felt either not very informed or not at all informed about clinical trials affirms the need to raise public awareness about clinical trials, so individuals are able to make better informed decisions. ${ }^{12}$ Indeed, initiatives are under way in the UK and in Australia to increase the public's awareness of clinical research. ${ }^{18,19}$ In the UK, though, it was found that increased awareness did not translate into increased willingness to participate. ${ }^{18}$

Respondents in our study were more inclined to identify societal benefits of clinical trial participation (advancing science and improving lives) and less inclined to identify personal benefits (free care and access to medical experts), as compared with the American study on which our study was modeled. ${ }^{20}$ This leaning toward societal over personal benefits may, at least in part, be associated with Canada's publicly funded health care system.

Surprisingly, there is little published in the peer-reviewed literature on this topic in the context of North America or Europe. Most is in the gray literature. Our findings are overall consistent with the closest contemporaneous equivalent: the CISCRP 2015 international study of public opinion of clinical trials. ${ }^{15}$ Generally, attitudes and variation across age, gender, and health were very similar. Our respondents' overall willingness to participate in research was closer to that of European 
Table 4. If You Were Thinking About Participating in a Clinical Trial, Where Would You Turn for Information?

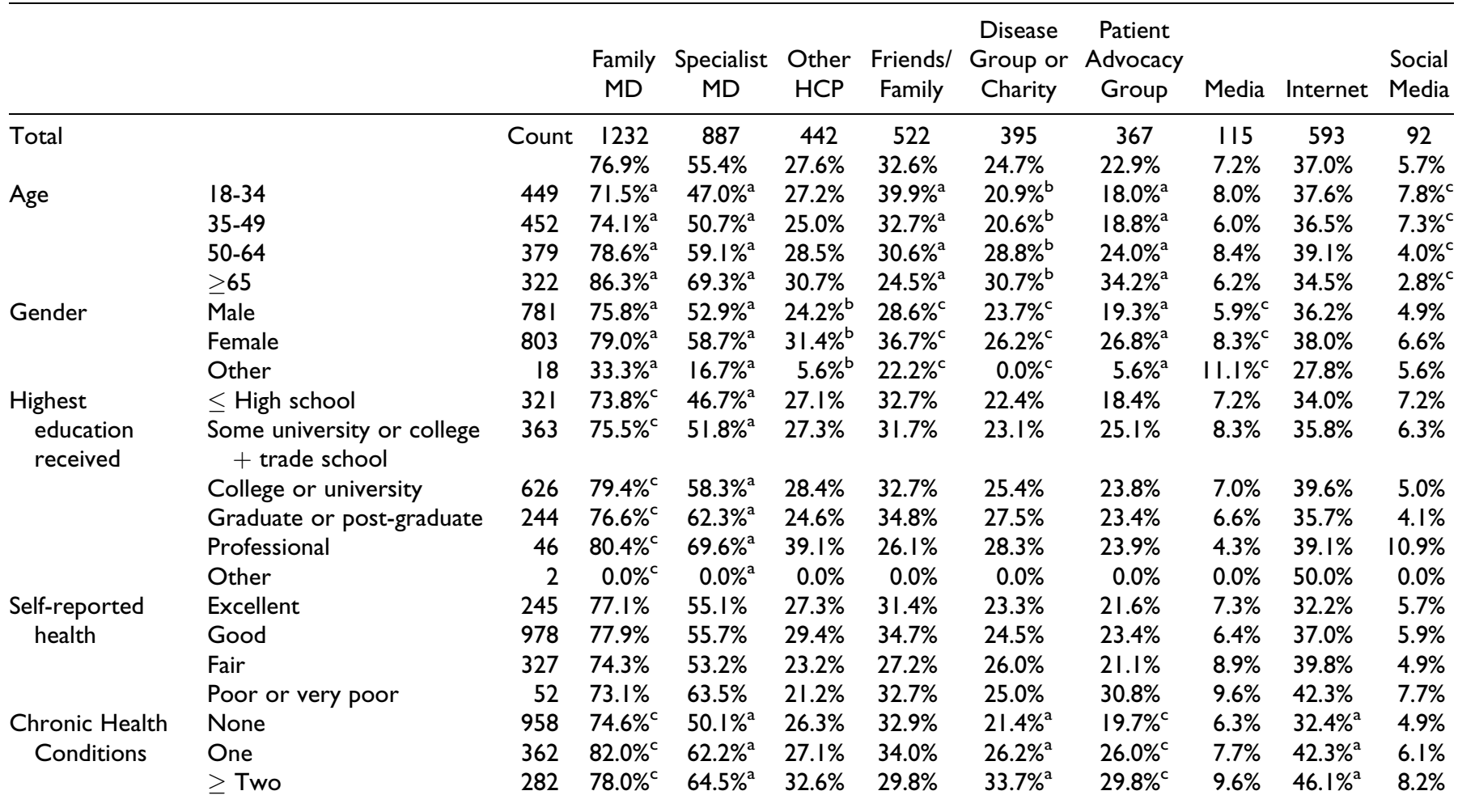

${ }^{\text {a Pearson }} \chi^{2} P=.000$.

${ }^{\mathrm{b}}$ Pearson $\chi^{2} P<.01$.

cPearson $\chi^{2} P<.05$.

respondents and less than the willingness of what the CISCRP study termed "North Americans" but which consisted almost exclusively of American respondents (Kenneth A. Getz, Tufts Center for the Study of Drug Development, personal communication, August 31, 2017).

\section{Limitations}

This study examined 2 provinces in Canada. While they represent approximately half of Canada's population, there are limitations to the generalization of our findings to other provinces. This is a start, and we hope there will be collection of similar data in other provinces. Our study measured only people's views in the abstract. When faced with an actual opportunity to participate, decisions may differ from stated attitudes. Potentially interested people may still not participate because of a number of factors, including aspects of the study protocol, inconvenience and lifestyle issues, and financial reasons. ${ }^{21}$ These logistical issues were explored in only a very cursory fashion. Also, we were not able to answer detailed questions such as why a respondent who had participated in research in the past answered in our survey that they would not again. This was a hypothesis-generating study to serve as an initial step in a larger patient engagement strategy. Therefore, only simple bivariate analyses were used to examine the association of several of the questions with age, gender, and self-reported health. No multivariable regression analyses were conducted to control for covariation. A small proportion of respondents who identified as neither male nor female responded quite differently from the rest of the sample. Though small numbers precluded drawing conclusions, this warrants further study. Finally, while the sampling method attempted to reproduce a representative population, we acknowledge that respondents consisted of a nonrandom sample of the Canadian population-particularly, those who participate routinely in online surveys.

\section{Conclusions}

We found generally positive attitudes toward clinical trials but considerable room for improvement in awareness and understanding of clinical trials. However, simply increasing public awareness of clinical research through the media may not increase participation. ${ }^{18}$ Indeed, we found surprisingly little reliance on both conventional and social media. With all the possible sources of information available to the public these days, it is striking that physicians are, by far, the most popular sources to which people would turn for information if contemplating entering a clinical trial—particularly one's family physician. This has been observed elsewhere. ${ }^{22}$ While this points to 
an important potential role for the clinician in helping patients wade through difficult decisions around clinical trial participation, clinicians generally have insufficient time in their patient encounters to engage on this subject. ${ }^{23-25}$ Nor are they generally trained in how to discuss with patients critical issues like medical uncertainty (equipoise), which is a precondition for conducting a clinical trial. ${ }^{26}$ Historically, since the 1979 Belmont Commission report, there have been careful attempts to distance the treating physician from the brokering of clinical trials. ${ }^{27,28}$ As we move toward practice-based research, the role of the family physician and other clinicians in assisting patients with such decisions must be addressed. ${ }^{29}$

\section{Declaration of Conflicting Interests}

No potential conflicts were declared.

\section{Funding}

This research was co-funded by Clinical Trials Ontario and the British Columbia Clinical Research Infrastructure Network (BCCRIN), now Clinical Trials BC.

Two of the authors (H.H. and S.M.) were heads of the funding organizations at the time of the study and three were paid consultants for the survey design (D.W., D.R., A.O.) and analysis (D.W.).

\section{Supplemental Material}

Supplemental material for this article is available online.

\section{Note}

i. Clinical Trials BC (formerly the BC Clinical Research Infrastructure Network (BCCRIN)) is part of the BC Academic Health Science Network.

\section{References}

1. Collier R. Federal government unveils patient-oriented research strategy. CMAJ. 2011; 183: 1469.

2. Schroen AT, Petroni GR, Hongkun W, et al. Preliminary evaluation of factors associated with premature trial closure and feasibility of accrual benchmarks in phase III oncology trials. Clinical Trials. 2010; 7: 312-21.

3. Canadian Cancer Research Alliance. Report on the state of cancer clinical trials in Canada. Toronto: Canadian Cancer Research Alliance, 2011.

4. Anonymous. Canada's Strategy for Patient-Oriented Research. Improving health outcomes through evidence-informed care. Ottawa: Canadian Institutes of Health Reserch, 2011.

5. Mansell P.Survey finds low awareness of clinical research as core NHS activity. PharmaTimes online. London, UK: PharmaTimes Media Ltd., 2012.

6. Massett HA, Dilts DM, Bailey R, et al. Raising Public Awareness of Clinical Trials: Development of Messages for a National Health Communication Campaign. Journal of health communication. 2017; 22: 373-85.
7. Townsley CA, Selby R, Siu LL. Systematic review of barriers to the recruitment of older patients with cancer onto clinical trials. Journal of Clinical Oncology. 2005; 23: 3112-24.

8. Nelson AM, Martin IG, Getz KA. Generational Value Differences Affecting Public Perceptions of and Willingness to Participate in Clinical Trials. Therapeutic Innovation \& Regulatory Science. 2015; 49: 940-6.

9. Burns KEA, Magyarody N, Jiang D, Wald R. Attitudes and views of the general public towards research participation. Intern Med J. 2013; 43: 531-40.

10. Jones JM, Nyhof-Young J, Moric J, Friedman A, Wells W, Catton P. Identifying Motivations and Barriers to Patient Participation in Clinical Trials. J Cancer Educ. 2007; 21: 237-42.

11. Getz KA. Public perceptions are turning the corner: public's view of clinical research has improved during the past five years, CISCRP survey reveals. Applied Clinical Trials. 2013; 22: 22.

12. Trauth JM, Musa D, Siminoff L, Jewell IK, Ricci E. Public Attitudes Regarding Willingness to Participate in Medical Research Studies. J Health Soc Policy. 2000; 12: 23-43.

13. Comis RL, Miller JD, Aldige CR, Krebs L, Stoval E. Public attitudes toward participation in cancer clinical trials. Journal of clinical oncology: official journal of the American Society of Clinical Oncology. 2003; 21: 830-5.

14. i-Say Ipsos Interactive Services Limited Partnership, p. https:// social.i-say.com/?0

15. Center for Information and Study on Clinical Research Participation. 2015 Perceptions and insights study. Report on public perceptions. . Boston2015.

16. CISCRP - The Center for Information and Study on Clinical Research Participation. p. https://www.ciscrp.org/.

17. Cobb EM, Gebremariam A, Singer D, Davis MM. Public Interest in Medical Research Participation: Does It Matter if Patients or Community Members Have Helped Design the Study? Clin Transl Sci. 2015; 8: 502-5.

18. Mackenzie IS, Wei L, Rutherford D, et al. Promoting public awareness of randomised clinical trials using the media: the Get Randomised campaign. Br J Clin Pharmacol. 2010; 69: 128-35.

19. Anonymous. \#WhyClinicalTrialsMatter A Social Campaign to Share the Value of Clinical Trials.

20. Center for Information and Study on Clinical Research Participation. 2013 Perceptions and Insights Study. Public and patient perceptions of clinical research. Report on general perceptions. Boston: Center for Information and Study on Clinical Research Participation, 2013.

21. Brintnall-Karabelas J, Sung S, Cadman ME, Squires C, Whorton K, Pao M. Improving Recruitment in Clinical Trials: Why Eligible Participants Decline. Journal of Empirical Research on Human Research Ethics: An International Journal. 2011; 6: 69-74.

22. Kelley M, James C, Alessi Kraft S, et al. Patient Perspectives on the Learning Health System: The Importance of Trust and Shared Decision Making. The American Journal of Bioethics. 2015; 15: 4-17. 
23. Eapen ZJ, Vavalle JP, Granger CB, Harrington RA, Peterson ED, Califf RM. Rescuing clinical trials in the United States and beyond: A call for action. Am Heart J. 2013; 165: 837-47.

24. Rendell Jennifer M, Merritt Rowena K, Geddes J. Incentives and disincentives to participation by clinicians in randomised controlled trials. Cochrane Database of Systematic Reviews: (2007).

25. Ross S, Grant A, Counsell C, Gillespie W, Russell I, Prescott R. Barriers to participation in randomised controlled trials: a systematic review. J Clin Epidemiol. 1999; 52.
26. Califf RM.Clinical trials in crisis: Four simple methodologic fixes Commentary. Clinical Trials. 2014; 11: 626-7.

27. Fischer BA. A summary of important documents in the field of research ethics. Schizophr Bull. 2006; 32: 69-80.

28. Friesen P, Kearns L, Redman B, Caplan AL. Rethinking the Belmont Report? The American Journal of Bioethics. 2017; 17: 15-21.

29. Califf RM, Sugarman J. Exploring the ethical and regulatory issues in pragmatic clinical trials. Clinical Trials. 2015; 12: 436-41. 